\title{
1. Subprime markets in global capitalism: history and contradictions
}

For the last decade or so, progressive intellectuals have been determined to understand the 2008 financial crisis. Immediately following the crisis, attention focused on the contradictory nature of neoliberal accumulation and the faulty and fraudulent risk management practices and financial innovations that destabilized core markets and crippled bank balance sheets. This literature got overly side-tracked declaring the speculative nature of financial accumulation, but nonetheless revealed the class origins of the crisis (Foster and Magdoff 2009; Baker 2009). Moreover, it recognized certain points of contact between the accumulation of US mortgage loans and the global savings glut in Asia. Even though this connection was frequently conceived in the narrowest terms, the contextualization offered by this view reflected a further attempt to see beyond surface events.

More recent perspectives have moved in a different direction, holding that the international transmission of US subprime mortgage debt reciprocally impacted US and European markets (Tooze 2018). Recognizing the transatlantic dimensions of the crisis, and its impact on the wholesale funding channels forming the nerve centre of global capitalism, this new literature shows that European banks used international money markets to accumulate risky mortgage bonds, and that this sustained and underpinned the dysfunctional conditions leading to the collapse (Aliber and Kindleberger 2015). ${ }^{1}$

Yet though these contributions highlight various scales of financial power, and important contradictions, their tendency to focus on the period immediately leading up to the collapse has produced only a partial accounting, one that strains against viewing deeper historical connections. Subsequently, the crisis has been detached from the Bretton Woods financial system and the perceived safety of US Treasury bonds. With this, an important opportunity has been lost to develop critical research, and avoid falling back on vague ideas that fail to grasp the complex forms of power centring financial markets. Developing this literature requires reframing the crisis and addressing the deficiencies in financial scholarship that obfuscate reality.

This book encourages readers to explore the long history of the subprime crisis through an approach to financial risk that challenges conventional understandings: it links both the crisis and its management to a new type of 
abstract risk launched in the post-Second World War era. This view takes issue with the common IPE (International Political Economy) account of financial rationality, which sees actors and institutions as risk takers, unconcerned with volatility, and contributes to the critical scholarship on the subprime collapse, both the older literature which emerged in the immediacy of the crisis and the newer literature which has surfaced over the last few years. At the same time, it offers new insight about the development of financial markets and US financial power.

By exploring the intersubjective meanings shaping the popularity of US debt, and the historical development of subprime markets, I take seriously the cultural turn in political economy, and resist attempts to explain financial flows in purely material terms. This is to argue that constructions of risk exist inside financial markets and that base-superstructure approaches, which separate semiotic orders from economic practice, erase many key forces and mechanisms shaping demand. The approach adopted by this book therefore addresses a slightly different set of questions: How did the postwar credibility of US financial instruments imprint on US and global financial markets? And most importantly: What is the relationship between conceptions of risk in the international bond market and the 2008 financial cloudburst?

This book also endorses the institutional turn in political economy. In the following pages we will notice that US risk power was constituted in specific institutional relations at the international level and acted through different policy decisions, which structured a certain type of outcome for financial firms, markets, and regulators. Moreover, we will see that these institutional properties influenced the historical path of the financial system, shaped the nature of US financial risk, and fashioned the particular trajectory of the subprime crisis.

\section{FRAMING MARKETS, STUDYING FINANCIAL POWER}

This book departs from what I have earlier called an institutional Marxist (IM) framework, ${ }^{2}$ and builds on the cultural political economy (CPE) tradition associated with Sum and Jessop (2013). It thereby adopts 'tools from critical semiotic analysis' and identifies institutional formations as important 'entry points' for studying the social world (ibid.: 140, 38). Such an approach also situates cultural and institutional forces within wider material relations, given that both IM and CPE build from the concept of emergence $e^{3}$ associated with critical realism, ${ }^{4}$ and offer a stratified view of the social world. 


\section{Cultural Turns in Critical Political Economy}

CPE highlights the semiotic (meaning making) nature of all social relations as well as the 'emergent non-semiotic features of social structure[s]' (Jessop 2014; 2015). It views the production of meaning as a necessary 'condition of going on in the world', since real life events cannot be grasped in all of their complexity (ibid.: np). This explains why meaning systems evolve - beyond the simple observation that humans are sentient, reflexive creatures - and centres the wider and deeper structural components of reality. CPE identifies three primary semiotic stages. First, before particular discourses are picked 'for interpreting events, legitimizing actions and ... representing social phenomena', the social landscape is characterized by a wide variation of 'construals', as actors draw on their own subjective experiences and agential powers (Sum and Jessop 2013: 185). Following this moment of variation, the selection of discourses occurs as individual construals are funnelled through extra-semiotic practices. This amounts to a process of structural selectivity as discourses are chosen, in part as agents interact with the generative mechanisms of wider strata. Finally, there is the retention of discourses involved in the 'enactment of meaning systems in organizational routines ... institutional rules, material and intellectual technologies' (ibid.: 185). This process of sedimentation leads actors to forget the 'contested origins' of semiotic meaning systems, giving 'them the form of objective facts of life' (Jessop 2015).

From this, Sum and Jessop distinguish between semiosis on the one hand and imaginaries on the other. The former refers to the production of shared meanings, the latter to a semiotic 'ensemble' that configures 'various genres, discourses, and styles around a particular conception of the economy and its extra-economic conditions of existence' (Sum and Jessop 2013: 165; Jessop and Oosterlynck 2008: 1158). Imaginaries frame 'individual subjects' lived experience of an inordinately complex world', but are not defined by their semiotic characteristics alone; they include the structural and institutional supports giving them force to shape the world and are thereby the 'creative products of semiotic and material practices' (Sum and Jessop 2013: 165, my emphasis). They are inherently durable and play a 'central role in the ... reproduction or transformation of the prevailing structures of exploitation and domination' (ibid.: 165).

Imaginaries 'exist at different sites and scales of action', and have 'more or less performative power', for they support a range of structural and institutional mechanisms, each with very different functions and organizational features (ibid.: 165). This focuses attention on the role of hegemonic imaginaries, which develop as social forces 'try to make one or another imaginary the ... dominant frame in particular contexts', and brings Sum and Jessop close to Gramsci's view of ideology (ibid.: 171). Yet the intentional manipulation of 
consciousness professed by Gramsci is not at work in the same way. This is what Sum and Jessop (2013: 170) mean when they say that 'imaginaries are based on different entry-points and standpoints' and do not necessarily 'privilege some entry-points and standpoints'. Though imaginaries can evolve into ideologies when material interests elevate their views to the level of common sense truth, they allow for a greater degree of openness and social learning, and are less intentional in their formation and ongoing reproduction.

This focus on the dialectical emergence of semiotic processes weds Sum and Jessop to critical realist social philosophy. At the same time, it extends the work of Bhaskar, Creaven and Collier by opening up the 'transitive' (theoretical, ideational, discursive) construction of knowledge and the layered process of meaning making. A key contribution is to show how imaginaries consolidate domination by structuring common sense everyday life patterns and are grounded in capitalist power relations.

However, the CPE model has its own lapses and problems to contend with. There is first a tendency, stemming from its incorporation of Jessop's Strategic Relational Approach, to trivialize and discount the wider structures that shape meaning systems. Indeed, Jessop argues that the dialectical relationship between different social strata relativizes the basic properties of real structures. This means that even the core features of capitalism - competition, exploitation, and for-profit production - can be altered without social struggle and changed unintentionally. Such a view denies the influence of capitalist social pressures 'in the last instance' and is in all essentials wrong. ${ }^{5}$ As a result, the CPE approach is valuable only insofar as it accounts for the durability, although not immovability, of real existing structural relations. This is to recognize, as Wendy Brown (2015: 76) has shown, that 'capitalism has drives that no discourse can deny ... to grow, to reduce input costs, to search out new venues of profit, and to generate new markets, even as the form, practices, and venues for these drives are infinitely diverse'.

Second, the CPE model fails to work out the relationship between institutional systems and social imaginaries. Its claim, that institutions are one part of the diffuse extra-semiotic landscape that sets cognitive frames and guides collective action, is empty of content: it is difficult to know whether institutions are important features of the non-semiotic social structure, and to what degree they sediment discursive frameworks to produce economic imaginaries. By contrast, institutional Marxism views the unfolding of objective history through institutional forms of organized power. This defines institutional rules and norms as concrete manifestations of the relationship between structural pressures and agential forces (their 'combination' in CR terms) and calls attention to how institutions sediment semiotic meaning systems.

A third problem arises from its narrow application. The CPE model has been used to explore semiotic practices, though not in a way that amends the 
separation between economic and discursive power. One of the major contributions of post-structural scholarship has been to recognize the always partial treatment of cultural systems within traditional base-superstructure research. By denying 'the separation of symbols/discourse/culture from material/structure/economics or culture/ideology/theory from politics/economics/practice', post-structuralists have opened 'technical and depoliticized practice to political scrutiny' (Peterson 2006: 120; de Goede 2006: 7, 14; de Goede 2003; 2005). ${ }^{6}$ Thus rather than simply viewing the emergent properties of cultural systems, we need to understand how certain economic relations are themselves formed through, or anchored in, discursive meaning systems. This is not to deny the existence of wider material practices - as in much post-structural research but to acknowledge that intersubjective meanings function as emergent strata within the economic 'base'.

\section{Institutional Turns: CPE and IM}

Beyond attributing institutions a role in the structuration process, CPE sees them as important in the selection of social construals, since they narrow options and privilege certain 'interests, activities and organizations' (Jessop and Oosterlynck 2008: 1156). This stems from a neo-institutionalist interpretation of the path-dependent and path-shaping characteristics of formal and informal institutional rules, norms, and codes of conduct. Borrowing from the work of Skocpol, ${ }^{7}$ Hall and Taylor (1996), and Thelen (1999), institutions are seen as providing 'a framework in which relevant actors can reach and consolidate agreement' (Sum and Jessop 2013: 62). The major point is that they 'stabilize the cognitive and normative expectations of ... actors by shaping and promoting a common worldview as well as developing ... the predictable ordering of various actions' (Jessop 2001: 1231).

Through this, CPE distinguishes between structural and institutional mechanisms. As 'path-dependent and path defining complexes of social relations' that are 'connected to specific forms of power and domination', institutions are given both 'microfoundations and macrocontext': they are 'sustained and instantiated in individual, organizational and interorganizational activities but they are also embedded ... in a complex ... societal formation' (Jessop 2001: 1217, 1222). This recognizes three important points: (1) that institutions sediment the relations established by structural mechanisms and 'assume the structures which operate through them'; (2) that 'institutional analysis occurs prior to action even if the action subsequently transforms institutions and institutional contexts'; and (3) that agents have the 'capacity to engage in learning and to reflect on institutional context, institutional design, etc.' (Maher and Aquanno 2018: 40; Jessop 2001: 1230). More generally, it draws attention to 
institutions as a 'complex emergent phenomenon', relatively autonomous from structural and agential forces (ibid.: 1230).

Unquestionably, this view of institutions furnishes an important break with core approaches to structural analysis, which have been hampered by the tendency to either ignore institutional properties altogether, or subsume them into wider structural ensembles. In the latter case, institutional rules are treated as structural accessories before being boiled down to the condensation of structural relations. This inhibits understanding of the dialectical interplay between structural relations and institutional rules, and robs institutions of any autonomous force: as passive carriers of structural logics, they cannot 'obey laws other than the structural laws within which [they] are rooted' or 'do things that could not be predicted from an analysis of the underlying structure' (Collier 1994: 116).

Yet CPE offers only a provisional starting point for understanding the ontological significance and emergence of institutions, as it provides no more than a blueprint for the formation or relative autonomy of institutional forces. Institutions and structures are all too often blurred together and the analytical basis for their separation is insufficiently explained. IM addresses these problems, pushing forward the institutional turn within CPE, by massaging Marx's base-superstructure framework into 'a thesis about vertical explanation' (Collier 1994: 48). Even if the economic structure is basic to the politico-ideological superstructure, the emergence of social mechanisms means the latter is somewhat autonomous from, and capable of acting back on and shaping, the former. This provides a narrower basis for understanding the totalizing logic of the economic base and brings the emergentist perspective close to Thompson's view of 'history as process' (Thompson 1978: 9). The effect is to substitute a teleological assessment of capitalism, in which the inner laws of production lead automatically to fixed outcomes, for recognition of the complex contingency, immense variety, and openness of capitalist social organization. If the economic structure exerts certain basic 'pressures' or 'situational logics', ${ }^{8}$ it does not issue structural laws which lead in 'monocausal fashion to social effects' (Thompson 1978: 9; Creaven 2000: 238, 275). ${ }^{9}$

From this stratified and vertical perspective, IM offers a more thorough understanding of institutional power and formation. It sees institutions as emergent properties that develop from the subjectivity of human agents and the objective conditions within which they are embedded - including, above all, the transfactual properties of capitalist social relations (Maher and Aquanno 2018: 36). This view, that institutions arise from the dialectical relationship between objective and subjective forces, recognizes the casual efficacy of agents and acknowledges that the 'moment of choice' is itself a 'structurally localized conjunctural element embedded within hierarchical causal relations' 
(ibid.: 36). Moreover, it sees institutions as the specific organizational manifestations of capitalist structural relations.

All this is to say that institutions profoundly shape the social landscape and are themselves constantly evolving. Institutions are key nodes of power because they constrain action, as in the traditional neo-institutional account (ibid.: 38). Yet, by drawing together different social resources and privileges and constructing organizational forms that allow struggles to be carried forward, they also form the 'very positive conditions that make possible the realization of foundational mechanisms' (ibid.: 38).

IM subsequently argues that institutions need to be placed 'at the center of the search for an explanation of the making of global capitalism', and that state capacities have been restructured, not absolutely eroded, with the liberalization of markets (Panitch and Gindin 2012: 1; Maher and Aquanno 2018; Konings 2011). This provides the basis for questioning the use of such concepts as embedded and disembedded liberalism, and views state/institutional power as separate from, but intermeshed with, economic power. It also problematizes the 'state versus market' approach characteristic of IPE scholarship, that sees neoliberalism and financialization undermining state institutional capacities.

To summarize and draw together the above content: this book works from within an institutional Marxist framework and draws on CPE to highlight the critical role of intersubjective meanings and institutional practices in the historical development of postwar financial markets. At the same time, it seeks to overcome certain weaknesses in the CPE framework by advancing three central arguments:

1. That institutions are emergent properties which evolve and develop through the combination of durable economic structures and discursively embedded human subjects;

2. That institutional formations, by both constraining and enabling action, shape the dynamics of economic change and development;

3. That institutions express and sediment discursive constructions that operate as cognitive locks and influence financial demand.

\section{THE LONG HISTORY OF THE SUBPRIME CRISIS}

With this outline in mind, we can pass back to the issue at the heart of this book. The present work is separated by its focus on the deep history of the subprime crisis. ${ }^{10}$ Here it is argued that the origins of the crisis are only poorly understood if we perceive the collapse of US mortgage debt separate from, rather than linked to, the specific evolution of abstract risk in the international bond market (IBM). 
This entails paying close attention to the IBM and stitching together data from the Organisation for Economic Co-operation and Development (OECD), the Bank of International Settlements (BIS), the US Treasury Department, and the US Federal Reserve, as well as other public and private organizations, to examine issuance and demand in this market since the 1940s. The book defines the IBM somewhat unconventionally as consisting of three central trading posts: the market for domestic-international bond issues; the foreign bond market; and the offshore market. ${ }^{11,12}$ Posing the history of the subprime collapse in this way also requires acknowledging the complex constitution of financial demand and its relation to risk. This book views financial demand in terms of the stratified vision presented by critical realism, cultural political economy, and institutional Marxism. It argues that financial markets are organized by diffuse, imperially constituted definitions of risk that have their basis in, but cannot be reduced to, material economic relations. This abstract form of risk is expressed as a financial common sense, offering a cognitive lock which reduces the complexity and uncertainty of financial exchange. The concrete forms of risk that we are much more familiar with - the forms which are quantified, measured and weighed against rates of return to construct investment portfolios - are emergent from, and subordinate to, this deeper system of financial control. I will argue that this view of abstract risk helps us understand why international demand for US debt has always vastly exceeded the United States' share of global GDP (Figure 1.1).

The approach taken by this book finds support in Keynes' position that popular social norms influence financial valuations. It is also connected to Weberian scholarship on the social relations of money, in so far as it sheds light on the ideational constitution of financial markets. Likewise, IPE studies of the global financial marketplace have done well to reveal the social and political basis of demand, filling some of the gaps left by Weberian-inspired theories of money and finance. Using what can be called a Political Economy of Monetary Relations Approach, IPE scholars have shown that financial markets rely enormously on state institutional resources and are configured by monetary systems developed at the international level (Block 1977; Helleiner 1994; 2003; 2009; 2010; Pauly 1997; Hall 2009). ${ }^{13}$ At the same time, these studies have focused on the unique international credibility of the dollar in serving US financial hegemony. IPE scholarship has been able to connect financial demand to state power and socially constructed ideas of credibility, and recognizes that norms of market confidence have primarily benefited the US dollar in the postwar period.

There are, however, a number of problems with this literature. Apart from simply asserting that market actors have special faith in the dollar, the most severe problem is that it neglects the emergent nature of financial ideas within the institutional channels of capitalist organization. The concept of risk imag- 


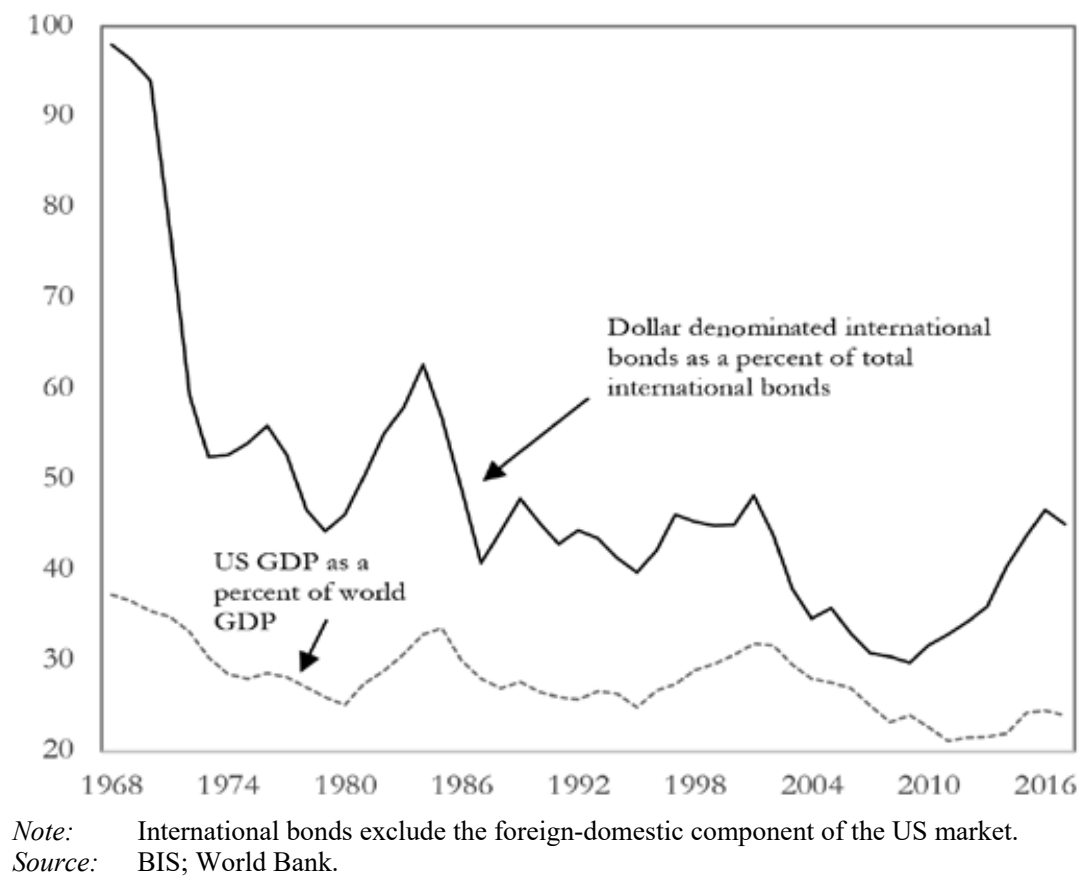

Figure 1.1 Dollar denominated international bonds and US GDP

inary is presented to animate the stratified forces shaping demand and show how key state and international institutions sedimented and reproduced US risk power. I argue that the Bretton Woods Accord formalized a new common sense around financial risk, ushering in a long period of US risk hegemony in the international bond market that reorganized wide swathes of the global financial system and set the conditions for the 2008 crisis. I argue, moreover, that financial branches of the US state formed a critical part of the institutional ensemble sedimenting US risk power. Developments in US state capacity underwrote the stable reproduction of the international monetary systems underpinning the credibility of US debt, and financial regulators mediated its particular expression by opening and closing opportunities, while at the same time acting to support and manage global debt markets. The approach adopted by this book therefore links up with IPE literature, but extends it by appreciating the power-laden definitions of risk penetrating debt markets.

Here we should push forward an obvious question which has bearing on the direction of the analysis: what is the special nature of the IBM that makes it important for studying the subprime crisis and exploring US financial power? 
First, it must be recognized that the choice to explore the IBM is not arbitrary but rather reflective of the specificity of the crisis. It is necessary to remember that US mortgage-backed securities (pools of individual mortgages linked together and sold as single debt obligations) are simply bonds, and that the accumulation of these issues in Europe and Asia marked a specific form of internationalization. If we set aside some of the instruments that turbocharged and extended volatility, and the short-term money markets through which these instruments proliferated, the crisis was rooted in the US mortgage bond market, and especially the international extension of this market. It was, as we will see, a crisis in the domestic-international branch of the IBM.

This last point is critical and deserves specific attention, for the crisis is still all too often treated as 'made in America'. It is indeed well understood that the crisis had global manifestations, yet this is typically seen apart from the initial catastrophe, often as a ripple of the decline in US consumer spending. This story is premised on a fundamental misreading of the global financial system, one that obscures the international extension of the US mortgage bond market. Framing the crisis in terms of the global circulation of debt - that is, the international bond market - connects it to the institutionalized forms of abstract risk that have governed financial markets from the 1940s. It also draws attention to the hub-and-spoke relationship between US and European markets. As we will see, European banks were drawing on dollar-based money markets as part of a decades-long strategy centred around the accumulation of dollar denominated bonds. It is this that sent global debt and wholesale markets into a sharp tailspin as defaults began echoing through the US subprime market.

By studying the IBM one also uncovers how global debt markets pivot around US Treasury bonds and private dollar denominated issues. Each segment of the market in fact reveals different dimensions of US risk power and offers insight into the institutional channels supporting international demand. The dominance of the Yankee bond market in the foreign section of the IBM shows that foreign banks and corporations were eager to acquire US dollars, and issued bonds in the US market as a way of obtaining dollar holdings. The historical development of the offshore Eurobond market further demonstrates strong demand for US dollars, but as Eurobonds were issued outside the US domestic market, it also more clearly shows foreign interest in dollar denominated bonds. In this respect, the prominence of the Eurodollar bond market (the dollar segment of the Eurobond market), especially as it was used by private US issuers to raise funds, laid the tracks for the US MBS market: it brought European investors into dollar denominated debt, and reflected strong European demand for US dollar placements. For its part, the US domestic-international market shows that international investors both sought bonds for their linkage to dollars and consistently demanded bonds backed by the US state, directly or indirectly. The private and public sections 
of this market further demonstrate trends in the Yankee and Eurodollar bond market, while showing that bonds backed by the US state have long been uniquely attractive to foreign investors.

The IBM thus offers an important perspective on the post-Second World War evolution of financial demand and the trajectory of the global financial system during this period. It shows that international investors have long been drawn to public and private US debt placements as a way of accumulating US Treasury obligations - dollars and bonds; and that the accumulation of US MBS by European and Asian investors, which brought the financial system to chaos in 2008, actually reflects a historical modelling of risk with roots in the evolution of financial markets during the 1930s and 1940s.

\section{THE VALUE OF RISK}

The historical-empirical analysis carried out by this book represents an essential extension of the critical scholarship, given its tendency to examine the crisis in terms of the dysfunctionality of capitalism and finance. ${ }^{14}$ The subprime collapse has often been viewed from the perspective of intertwined accumulation problems, of which tendencies towards over-production and under-consumption, the decline of the US empire, and the irresolvable contradictions of financialization are major traits. ${ }^{15}$ Yet for all its contributions, most of this work spends too little time understanding the crisis at the level of financial relations and its interconnectivity with the European 'sovereign debt' crisis. Of greater importance, this work ignores the deep seated patterns of control within the financial system that reinforce rather than undermine US imperial power.

Indeed, the connection between US financial power and US risk power has so far only been touched on. The critical political economy literature has tended to view financial markets in opposition to risk management, as a part of the inherently speculative nature of financial accumulation. This makes it very difficult to understand how the financial system is underpinned by imperial constructions of risk that shape financial demand, and leaves the literature with a vaguely conceived (and non-emergentist) view of financial 'credibility'. Moreover, US financial power is frequently linked to the rise of neoliberal globalization in the 1970s. ${ }^{16,17}$ Distinguishing the pre- and post-Bretton Woods period in this way ignores how US financial power has always been anchored in the liberal international institutions developed immediately after the Second World War. The collapse of the Bretton Woods system no doubt led to new forms of financial control. But this did not occur in opposition to the hub-and-spoke relations already connecting US and European markets. Rather, it took shape from the institutional and discursive patterns established in the 25 years following the war, which placed US Treasury bonds at the 
centre of the financial system. Here it is shown that the institutionalized forms of risk developed in the 1940s have always been part of the mechanisms underpinning US financial hegemony.

\section{OUTLINE AND CHAPTER OVERVIEW}

Chapter 2 works through the relationship between financial markets and financial risk. ${ }^{18}$ The argument takes issue with the standard way of viewing and calculating financial risk, which merely stacks up different quantitatively determined market uncertainties: credit risk, liquidity risk, interest rate risk, currency risk, repayment risk, and so on. Moreover, it contests the common image offered in the critical scholarship, which sees investors as speculative, irrational, and insensitive to risk and volatility. Against these narrow views, I argue that international debt markets operate through abstract conceptions of risk tied to imperial power. Chapter 3 builds the concept of risk imaginary from this understanding of abstract risk, working with IPE literature. It argues that the Bretton Woods international monetary system developed in the 1940s, like the dollar standard which followed in the 1970s, formalized a broad understanding about the risklessness of US debt obligations that acted as an interpretive framework for global firms and investors.

Chapter 4 starts the second part of the book and begins to trace the postwar development of the international bond market, as a way of exploring the deep history of the subprime crisis. Focusing on the period from 1945 to 1978, it shows that the abstract formation of risk laid down by the Bretton Woods system supported demand for US debt precisely because these issues could be tied back to the credibility of the US state. It also starts to unfold the complex interplay between US financial institutions and the postwar risk standard in showing how policy decisions influenced the concrete expression of financial demand. Chapter 5 continues this historical account, tracing the development of the IBM from the end of the 1970s to the mid-2000s. It reveals a similar pattern of demand across all three sections of the IBM, showing again that the evolution of financial markets involved both institutional and intersubjective forces coming to bear on the demand for dollar denominated debt. This overview clarifies how the evolution of the IBM set the tracks for the global expansion of US mortgage debt in the late 1990s and early 2000s. Chapter 6 traces the institutional ramifications of US risk power in the international bond market. Standing as the pivot of the IBM, US Treasury debt set down the conditions for a transatlantic hub-and-spoke financial system centred around Wall Street. As this system developed in the 1960s, key European financial circuits became tied into short-term dollar funding markets, and firms in London and across the continent stockpiled US debt obligations, both for their own portfolio and to sell to their clients. Chapter 7 examines the supervisory 
mechanisms which sustained US risk power in the period leading up to the 2008 crisis. It argues that US financial regulators played a key role managing the IBM throughout the post-Second World War period, and did so in a way that strengthened the dollar basis of global debt markets.

Building on this backdrop, Part III looks closely at the subprime crisis, specifically in terms of the financial relations and conventions underwriting the development of subprime finance, and how the US state managed the operation of critical market channels. Chapter 8 shows that global demand for US mortgage debt developed from a series of portfolio transfers within the IBM, as investors continued to privilege US public and private debt placements due to their perceived risklessness. It also shows that the crisis unfolded out of the institutional legacies and practices that took shape from the development of the IBM in the post-Second World War period - that the expansion of US subprime debt relied on the very same hub-and-spoke financial system that emerged through the accumulation of US debt in the 1960s and 1970s. Chapter 9 extends this discussion with focus on how US financial regulators managed to prevent the crisis from completely destroying the global financial apparatus. We see that regulators managed the collapse of US subprime and MBS markets not only by manipulating the credibility of US bonds, but by drawing on the lessons they previously acquired supervising demand in the IBM in the post-Second World War period. At the same time, they managed the subprime crisis in a way that extended US risk power, repeating previous actions and further internationalizing dollar denominated bonds. I conclude the book by drawing attention to the political underbelly of US risk power, speculating on the future of US financial hegemony by looking at the post-crisis evolution of financial demand. Specific focus is given to the institutional level transformations occurring at the Federal Reserve and their ability to contain key contradictions.

\section{NOTES}

1. From this perspective the subprime collapse resembles a typical foreign capital inflow banking crisis (Aliber and Kindleberger 2015).

2. See: Konings (2008; 2011); Panitch and Gindin (2005; 2006; 2012); Maher and Aquanno (2018).

3. The concept of emergence also describes the relative autonomy of internally connected structures (Archer 1995: 14). By granting the separation or uniqueness of each stratum against the inescapable rootedness of more complex structures in less complex aspects of reality, it captures the social world as a 'differentiated totality' characterized on the one hand by the 'directional logic' and 'constitutive role' of wider structures, and on the other by the 'totally novel power within each layer' (Creaven 2000: 34, 59, 41). Subsequently, while the generative mechanisms of emergent strata exert unique effects on concrete reality, by nature of their different form and function, deeper structures have a long-run tendency to 'assert 
their movement as necessary' (ibid.: 9). However, neither the evolution of higher order objects from lower level mechanisms, nor the boundedness of the former in the latter, implies a one-way relation of connectivity: because 'the parts are not pure functions of the whole, but go in their own way as well', the unique causal powers of higher order objects are 'capable of reacting back' on their constituent lower level mechanisms (Collier 1994: 117, 110, 113; Archer 1995: 9). This dialectical interplay further designates the complexity of real objects, necessitating spatial-temporal analysis of emergent properties and signifying the dynamism and fluidity of structural tendencies.

4. Developed prominently from the work of Roy Bhaskar $(1978 ; 1986 ; 1989)$, critical realism (CR) argues that social outcomes are the product of 'relatively enduring structures' (ibid.: 16). As Bhaskar notes, a strong realist position directs both explanatory and emancipatory focus to the social structures which 'pre-exist ... (but nevertheless depend for their reproduction and are transformed by) the individuals who enter into them' (Bhaskar 1989: 4). In this sense, CR presents a deep view of reality that 'looks beneath the course of events to the mechanisms that generate it', and argues that social realities are intransitive and structured (Collier 1994: 50). This ends up separating between three domains of reality: the empirical, the actual and the real. Whereas the empirical is 'defined as the domain of experience' and individual observation, the actual refers to experiences and unobserved events (ibid.: 44). It is only at the third level of reality that we encounter the organizing structures of natural and social existence (Sayer 2000: 11; 1992). This conception of structural depth can therefore be expressed in the explanatory primacy acceded to the domain of the real, since the focus on deep structures is well founded only if 'real world events are comprehensible in terms of underlying structures and attendant generative mechanisms' (Creaven 2000: 26). Yet this does not simply mean that the causal powers and generative mechanisms of underlying structures are transparently displayed in the actual and empirical realm. In noting the counter-phenomenality of knowledge, CR argues that 'the deep structure of something may not just go beyond, and not just explain, but also contradict appearances' (Collier 1994: 7). The work of science in understanding reality and constructing theory (the transitive dimension) subsequently involves moving from the socially mediated realm of the concrete and complex to the abstract and simple layer of deep mechanisms and antecedent structures (the intransitive dimension). This in turn leads to a retroductive method of argumentation, whereby analysis advances 'from a description of some phenomenon to a description of something which produces it or is a condition for it' (Bhaskar 1986: 11). From this view, the domain of the real is in fact a 'hierarchically ordered world of distinct strata governed by causal relations of ... determination', where less complex layers of reality are assumed within and condition more complex layers of reality (Creaven 2000: 29). Though this views higher strata as 'governed by different kinds of laws,' their emergence from less basic strata lays the foundation for a truly stratified view of nature (Collier 1994: 191). For Bhaskar, higher order strata are 'new phenomena' which emerge not from the conscious or deliberate workings of lower order strata, but rather from the 'specific interaction or combination of generative mechanisms internal to those objects or structures which exist ... immediately basic to it' (Bhaskar as quoted in Creaven 2000: 31).

5. Jessop's Strategic Relational approach therefore leads us away from critical realism and towards analytic individualism. See Jessop (2001).

6. See also: Hasselstrom (2000). 
7. See Evans et al. (1985).

8. The extent to which Creaven endorses this view is a little uncertain. While he recognizes the contingency of societal pressures, his analysis also hints at the persistence of certain capitalist logics (i.e., over-production and under-consumption). As a result, his point seems softer than Thompson's: that laws exist but are not necessarily activated. For Thompson (1978), there can be no understanding of certain laws within real existing capitalism due to the dialectical evolution of capitalist social and economic relations and the force of human agency.

9. Emergent Marxism balances against the extreme contingency view offered by Jessop's Strategic Relational Approach which, if pushed to its logical end, relativizes even the basic properties of capitalist organization. The potential of this project to relativize even the basic class relations of capitalism has made it a popular tool of non-Marxist scholarship looking to add a deeper structural aspect to their work without advocating the primacy of capitalist social organization.

10. It is important to emphasize that the deep history of the subprime crisis has been neglected in the critical scholarship. This is at least partly because the financial practices immediately responsible for the meltdown - securitized subprime mortgage debt, shadow banking, credit default swaps - are themselves relatively new.

11. The domestic-international segment consists, most notably, of the foreign branch of the US Treasury bond market. The foreign bond market can itself be sectioned into a series of distinct bond markets, the most notable of which are those of major industrialized nations, particularly the United States, Japan and Switzerland. The offshore market consists of the Eurobond market and the global bond market.

12. This is not a common definition of the international bond market. Most studies view the IBM in much smaller terms, as either including the foreign bond market and the offshore bond market, or just the latter. The problem with these definitions is that they fail to see how more traditional bond markets engender international linkages between buyers and sellers. In this sense, common definitions create a distinction between traditional national/onshore markets and newer non-national markets. Yet, national markets also have distinct international features. This book defines the IBM to include the foreign owned segments of onshore markets as these reveal patterns of international demand in exactly the same way as foreign and offshore markets.

13. Other IPE scholars who have made similar important contributions, noting in particular the relationship between financial markets and state power, include: Versluysen (1981); Gowa (1983); Frieden (1987); Hawley (1987); Henning (1994); Eichengreen (1996); Burn (1999); Underhill (2003); Langley (2002); Porter (2005); Sinclair (2005); and Best (2005).

14. In particular see: Brenner (2008); Wade (2008); Blackburn (2008); Foster and Magdoff (2009); Harman (2009); Kliman (2008); Lapavitsas (2009); McNally (2008); Nesvetailova and Palan (2008) and Balakrishnan (2010). Also Nesvetailova (2007) has presented a very good analysis of financial crises in contemporary capitalism.

15. Studies on the subprime crisis have also focused on the irrational behaviour of global traders and US homeowners (Muolo and Padilla 2008; Goodman et al. 2008; Shiller 2008; Cohen 2009; Posner 2009; Zandi 2009), patterns of inequality within the US mortgage market (Dymski 2010), and the wider cycle of financial accumulation and growth that supported subprime issuance (Schwartz 2009a).

16. That financial flows not only following the Second World War but up to the present reveal and reinforce US imperial power is a position clearly at odds 
with the frameworks offered by Arrighi (1994), Moseley (1999), Brenner (2002; 2004), Callinicos (1999; 2006), Kliman (2008), and Foster and Magdoff (2009). These scholars tend to argue that the US balance of payments deficit, as well as deepening speculation in US capital markets, is a symptom of a wider crisis of accumulation and profitability.

17. In presenting the major notable critique to this scholarship, Panitch and Gindin $(2005 ; 2012)$ argue that it is precisely because this scholarship finds weakness where it should find strength that it pushes aside sequences of power that unite the period following 1944. In suggesting that patterns of financial risk problematize views that chronicle the fissure of US imperialism and indicate instead that neoliberal financial relations have also been consolidated along the lines of US power, this study can be seen to build from the critical insights offered by Panitch and Gindin, especially their very strong research on the productive and economic dynamism of the US economy following the 1970s. In particular, this book asserts the presence of a post-Second World War risk imaginary on the basis of the wider structures of US postwar imperial capacity made clear in Panitch and Gindin's The Making of Global Capitalism.

18. This chapter draws on and develops an article I previously published in New Political Science, titled 'Institutional Power and the Risk of Finance' (42:2, pp. 139-54). The sections that have previously been published are reprinted with the permission of Taylor \& Francis, through their open access copyright licence. 